\title{
Microstructure and Properties of Ni-Zn Ferrites Sintered from Slip Cast Colloidally Precipitated Particles
}

\author{
T. Y. TSENG AND J. C. LIN
}

\begin{abstract}
Microstructural dependence of magnetic permeability and magnetic loss of $\mathrm{Ni}-\mathrm{Zn}$ ferrites sintered from slip cast colloidally precipitated ultrafine particles was investigated. A low-loss $\mathrm{Ni}-\mathrm{Zn}$ ferrite $\left(\tan \delta / \mu_{0}=4.92 \times 10^{-5}\right.$ at $\left.1 \mathrm{MHz}\right)$ having nearly maximum attainable density, fairly uniform and small grain size, and no significant zinc loss, was prepared by sintering at $1100^{\circ} \mathrm{C}$. There was considerable discrepancy in the permeability-grain size relation between $\leq 1100^{\circ} \mathrm{C}$ sintered ferrites and $>1100^{\circ} \mathrm{C}$. sintered ferrites. The zinc loss and intragranular pores in $>1100^{\circ} \mathrm{C}$ sintered ferrites may explain this discrepancy.
\end{abstract}

\section{INTRODUCTION}

L OW magnetic loss is a principal objective in the development of soft ferrites. In order to achieve this goal, it is necessary to carefully control the manufacturing process for obtaining the desired microstructure which includes high density and a small, uniform grain size. However, "high density" and "small grain size", are difficult to achieve simultaneously in the conventionally practiced sintering process without the use of additives. Recent works have shown slip casting of chemically coprecipitated particles to be a powerful method for obtaining homogeneous as-cast green microstructures, which, after sintering, have yielded high-density, fine-grained $\mathrm{Ni}-\mathrm{Zn}$ ferrite and barium ferrite, respectively, [1], [2].

In the present work, the primary objective was to correlate the sintering temperature and microstructure with the electrical and magnetic properties of fine-grained $\mathrm{Ni}$ $\mathrm{Zn}$ ferrites obtained via the ultrafine particle process that was developed.

\section{EXPERIMENTAL}

The material used in preparing the specimens consisted of chemically coprecipitated powders with the nominal composition $\mathrm{Ni}_{0.5} \mathrm{Zn}_{0.5} \mathrm{Fe}_{2} \mathrm{O}_{4}$. The powder particles were nearly spherical and ultrafine in size, on the order of 100 to $300 \AA$ (this was confirmed by scanning electron microscopy, SEM). X-ray diffraction indicated that these coprecipitated powders were crystalline. Toroids of 25 $\mathrm{mm}$ OD, $10 \mathrm{~mm} \mathrm{ID,} 8 \mathrm{~mm}$ in thickness; and pellets of 2 $\mathrm{mm}$ in diameter, $10 \mathrm{~mm}$ in thickness were formed using

Manuscript received October 17, 1988; revised April 24, 1989 The authors are with the Institute of Electronics, College of Engineer ing, National Chiao-Tung University, Hsinchu, Taiwan, Republic of China IEEE Log Number 8929193 slip casting of maximum deflocculation slurry (i.e., one showing nearly Newtonian flow behavior). This maximum deflocculation slurry, consisting of coprecipitated ferrite powders and deionized water, was obtained through proper control over the rheological properties. The slip behavior of this system was characterized by rheological measurements. The influences of process variables, including $p \mathrm{H}$ adjustment, slip solid loading, and dispersant (ammonium citrate) addition on the rheology, were considered. The detailed precipitation and casting processes were reported elsewhere [1]. The green bodies were fired in static air by heating from ambient at a rate of $15^{\circ} \mathrm{C} / \mathrm{min}$ to selected temperatures in the range of $1000-1200^{\circ} \mathrm{C}$. The samples were held at temperatures for $5 \mathrm{~h}$ and cooled to room temperature at an average rate of $30^{\circ} \mathrm{C} / \mathrm{min}$.

The densities of the sintered samples were measured by the Archimedes method. The true powder density of 5.35 $\mathrm{g} / \mathrm{cm}^{3}$ was obtained using a stereopycnometer (Quantachrome, New York, USA). The sintered samples were sectioned and polished using standard ceramographic procedures. Polished samples for viewing by SEM were thermally etched to make the grain boundaries visible. For accurate quantitative microscopy, a short etching time was chosen to avoid grain growth. Samples were etched for 20 $\min$ at $50^{\circ} \mathrm{C}$ lower than their sintering temperatures. Average grain size was determined by the linear intercept method from SEM micrographs of the thermally etched polished surfaces [3]. The complex initial permeability, $\mu_{0}=\mu^{\prime}-i \mu^{\prime \prime}$, was measured on the toroids at $1 \mathrm{MHz}$ with an LCR meter (HP 4257A, USA) using a 30-turn winding. Electrical resistivity was measured between gold electrodes applied to both sides of pellet samples.

\section{Results AND Discussion}

The as-sintered density and the theoretical percent achieved densification, calculated relative to the 5.35 $\mathrm{g} / \mathrm{cm}^{3}$ measured for the powder, as a function of sintering temperature are presented in Fig. 1. Densification almost ceased at $1100^{\circ} \mathrm{C}$ when the sintered density reached 98 percent of theoretical density. The ultrafine particle size and relatively uniform green microstructure (confirmed by SEM) are believed responsible for achieving this very high level of densification at the low temperature of $1100^{\circ} \mathrm{C}$, compared to much higher temperatures normally em- 


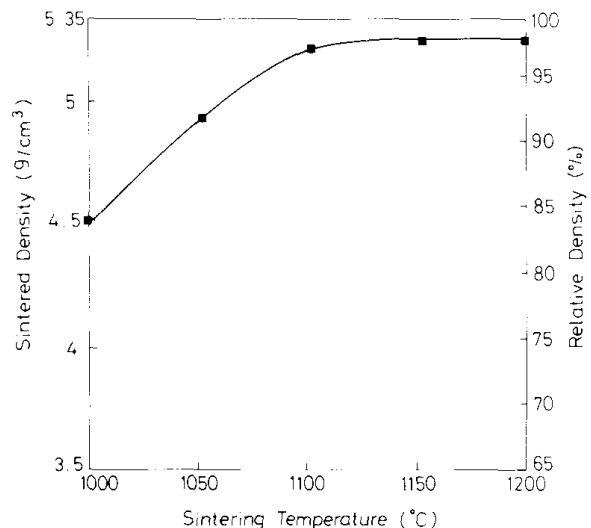

Fig. 1. Plot of sintered density and relative density versus sintering tem perature for samples sintered for $5 \mathrm{~h}$.

ployed with the conventional process $\left(-1300^{\circ} \mathrm{C}\right)$. The inability to reach theoretical value was attributed to the ferrite particle being too fine to be completely dispersed in the liquid suspension and, therefore, flocculated to some extent by Van der Waals bonding. This slightly flocculated suspension resulted in some small agglomerated regions distributed in the microstructure of the as-cast toroids. This was confirmed by SEM. Rearrangement and differential microdensification processes could not, thus, be wholly avoided during the sintering of these slightly inhomogeneous packed compacts and therefore completely dense fired bodies were not achieved.

The microstructures of the sintered specimens shown in Fig. 2 indicate relatively uniform grains with the porosity situated solely at the grain boundaries. The use of high surface area colloidally precipitated ferrite powders is believed to be responsible for the appearance of the intergranular porosity [4]. The observed low levels of nonuniformity in grain size most likely occurred as a consequence of slight inhomogeneities in the powder compacts. Figs. 1 and 3 show simultaneous grain growth and densification at temperature range of $1000-1200^{\circ} \mathrm{C}$. At $1100^{\circ} \mathrm{C}$ the compact densified readily up to about 98 percent of the theoretical maximum and the grain size in creased to about $1.5 \mu \mathrm{m}$. At temperatures greater than $1100^{\circ} \mathrm{C}$, significant grain coarsening occurred with the grain size increasing to about $2.2 \mu \mathrm{m}$ at $1200^{\circ} \mathrm{C}$

The relation between the permeability (real part and imaginary part) and the sintering temperature is given in Fig. 4. Higher permeability values were obtained with increasing temperature for the samples sintered below $1150^{\circ} \mathrm{C}$. Magnetic permeability $\left(\mu^{\prime}\right)$ decreased with increasing sintering temperature above $1150^{\circ} \mathrm{C}$. It was reported that achieving high magnetic permeability in ferrites requires careful optimization of many factors such as large, homogeneous grains, chemical homogeneity (because of which zinc evaporation. which causes strain and variation in $\mathrm{Fe}^{+3}$ content, has to be kept as low as possible), and little or no second phase [5]-[7]. Therefore, the peaking of the permeability in the 1100 to $1150^{\circ} \mathrm{C}$ (a)

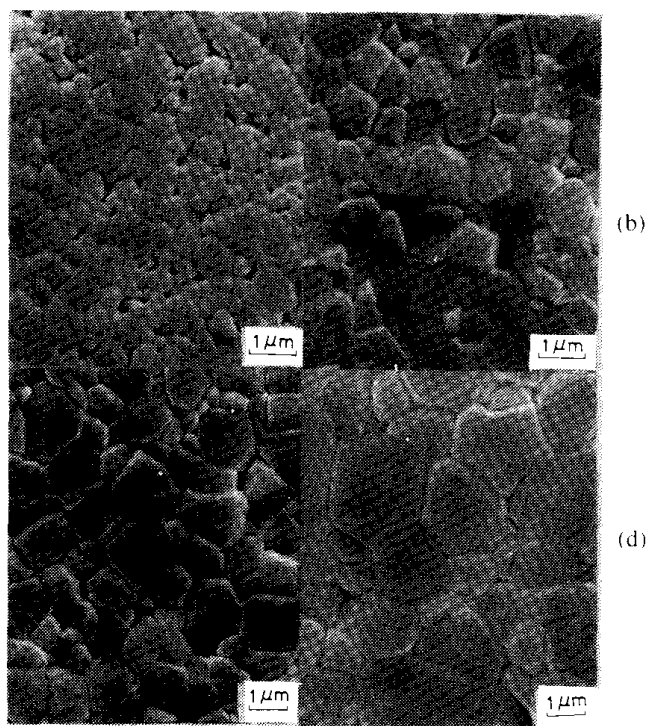

Fig. 2. Scanning electron micrographs of samples sintered at different temperatures for $5 \mathrm{~h}$. (a) $1000^{\circ} \mathrm{C}$. (b) $1050^{\circ} \mathrm{C}$. (c) $1100^{\circ} \mathrm{C}$. (d) $1200^{\circ} \mathrm{C}$.

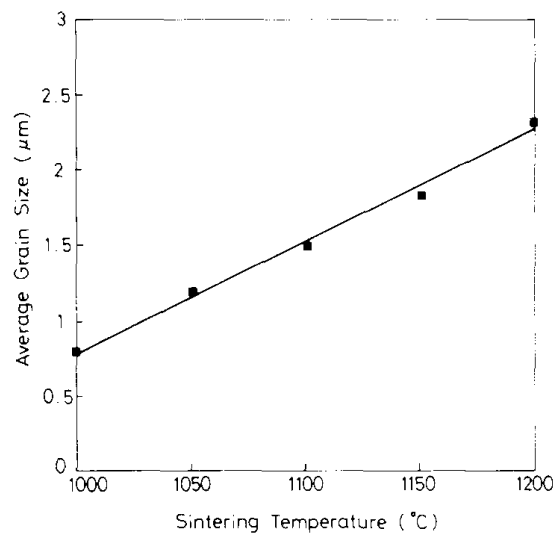

Fig, 3. Average grain size versus sintering temperature for sample sintered for $5 \mathrm{~h}$.

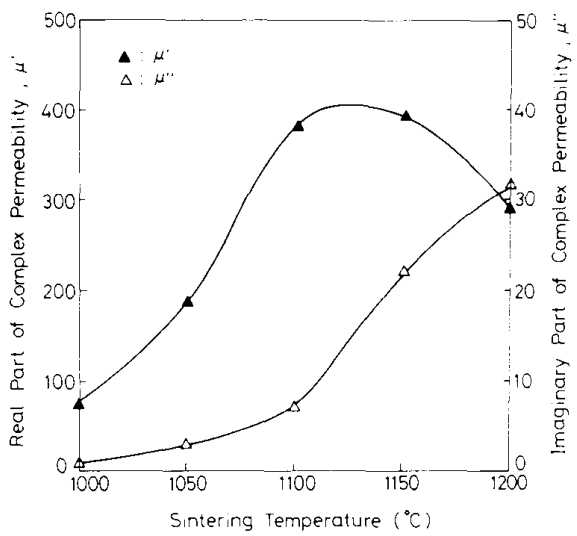

Fig. 4. Real part and imaginary part of complex permeability versus sintering temperature for samples sintered for $5 \mathrm{~h}$. 
range might be attributed to a larger achieved grain size, compared to the samples sintered at $\leq 1100^{\circ} \mathrm{C}$, and less zinc loss, compared to samples sintered at $\geq 1150^{\circ} \mathrm{C}$.

The imaginary (magnetic loss) part of the complex permeability $\left(\mu^{\prime \prime}\right)$ steadily increased with increasing sintering temperature. Its increase correlated with increasing grain size. This phenomenon is similar to that previously reported [6]. The magnetic loss is related to many causes, e.g., rotation of magnetization and domain-wall displacement. The fraction occupied by the domain-wall part will increase if the grain size is large; this will increase microscopic eddy current and hysteresis losses [8]. Also, zinc loss would result in increased ferrous ion concentration which will, additionally, cause eddy current loss increases. These might be the reasons why the magnetic loss increases much more rapidly for samples sintered at temperatures higher than $1100^{\circ} \mathrm{C}$. The evidence of zinc loss is discussed in Fig. 5. It shows the $\mathrm{X}$-ray diffraction patterns of samples sintered at 1100 and $1200^{\circ} \mathrm{C}$ for $5 \mathrm{~h}$. It indicates that the $\mathrm{X}$-ray pattern of the sample sintered at $1200^{\circ} \mathrm{C}$ was shifted to higher $2 \theta$ value compared to that of the sample sintered at $1100^{\circ} \mathrm{C}$. Consequently, the lattice constant of the sample sintered at $1200^{\circ} \mathrm{C}$ is expected to be lower than that of the $1100^{\circ} \mathrm{C}$ sample. This difference is believed to be associated with zinc loss at $1200^{\circ} \mathrm{C}$. Tasaki and Ito [9] have reported significant volatilization of zinc in $\mathrm{Ni}_{0.5} \mathrm{Zn}_{0.5} \mathrm{Fe}_{2} \mathrm{O}_{4}$ for sintering temperatures higher than $1200^{\circ} \mathrm{C}$ leading to lowered values of the lattice constant.

Fig. 6 shows the relation between the dc resistivity of sintered samples and the sintering temperature. The decrease in resistivity as a result of increasing sintering temperature can be attributed to the following reasons: 1) When sintering temperature increases, the grain size increases and the grain boundary decreases. The decrease of high resistive grain boundaries results in low resistivities of bulk samples. 2) The divalent iron content in Ni$\mathrm{Zn}$ ferrites is expected to be increased with volatilization of zinc [10]. With the increase in ferrous ions, the resistivity of the sample will decrease through the thermally activated hopping mechanism [11].

Grain boundaries generally act as pinning sites for the domain wall and the magnetic poles appear on the grain boundary surfaces. Based on Globus $e t$ al.'s equation relating the permeability with the grain size [12] and Chikazumi's wall spacing in a spherical grain [13], Igarashi and Okazaki [7] have given a relation between apparent permeability of the model and the grain size

$$
\mu_{\mathrm{app}}-1 \propto \frac{\Delta V}{V} r^{-1 / 2} \propto r^{1 / 2}
$$

where $\mu_{\text {app }}$ is apparent permeability, $\Delta V / V$ is the volume change of the domain per unit volume, and $r$ is the radius of the sphere of the crystallite grain. Their measured result of permeability was proportional to (grain size) $)^{1 / 3}$ which did not agree with their relation. The discrepancy was explained as arising from the domain wall being fixed

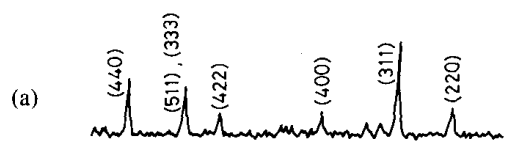

(b)

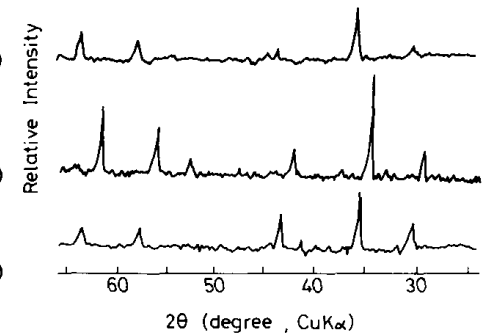

Fig. 5. X-ray diffraction patterns of sintered samples at different sintering temperature for $5 \mathrm{~h}$. (a) $1100^{\circ} \mathrm{C}$ as-sintered surface. (b) $1200^{\circ} \mathrm{C}$ as-sintered surface. (c) $1100^{\circ} \mathrm{C}$ fracture surface. (d) $1200^{\circ} \mathrm{C}$ fracture surface.

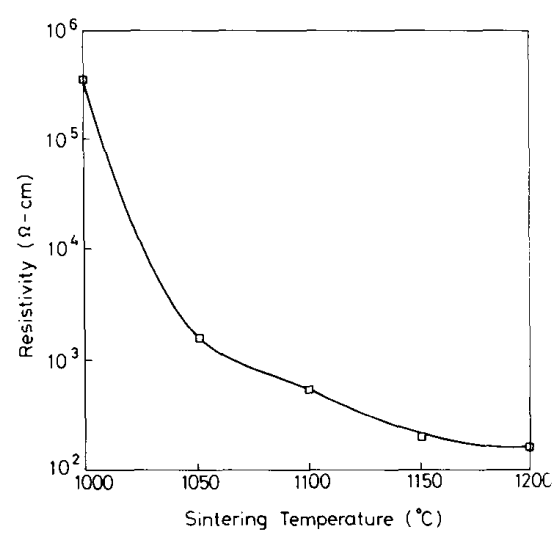

Fig. 6. Plot of resistivity versus sintering temperature.

also by pores located inside the grain while their relation applied to the case where the domain wall was fixed only by the grain boundary. Fig. 7 presents the measured magnetic permeability for the samples sintered in this study. At temperatures below $1100^{\circ} \mathrm{C}$ the permeability was proportional to (grain size) ${ }^{1 / 2}$, which was in good agreement with their relation, while the measured permeability and grain size for the samples sintered at temperatures higher than $1100^{\circ} \mathrm{C}$ deviated substantially from their relation. This discrepancy might arise from the zinc loss of the samples. Furthermore, the zinc loss may cause cation vacancies variation in the $\mathrm{Fe}^{+2} / \mathrm{Fe}^{+3}$ ratio in the $>1100^{\circ} \mathrm{C}$ sintered samples and, consequently, may reduce the sinterability and give rise to a microstructure with intragranular pores [14]. The possible pore entrapment within the grains in the samples sintered at temperature $>1100^{\circ} \mathrm{C}$ perhaps causes some of the deviation accounting for both decreased permeability and increased losses in those samples.

Fig. 8 shows the dependence of $\tan \delta / \mu_{0}(\tan \delta=$ $\left.\mu^{\prime \prime} / \mu^{\prime}\right)$ on the sintering temperature. It has a minimum value about $4.92 \times 10^{-5}$ at $1 \mathrm{MHz}$ for the sample sintered 


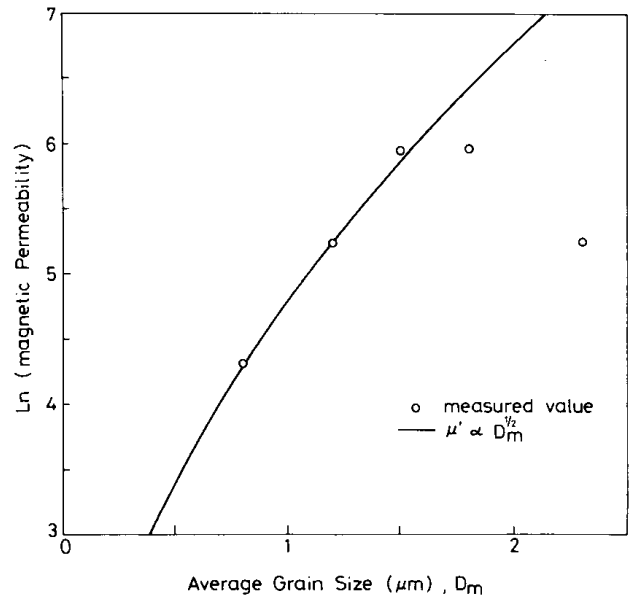

Fig. 7. Plot of magnetic permeability versus average grain size. Comparison is made between data (points) and Igarashi and Okazaki relation (line).

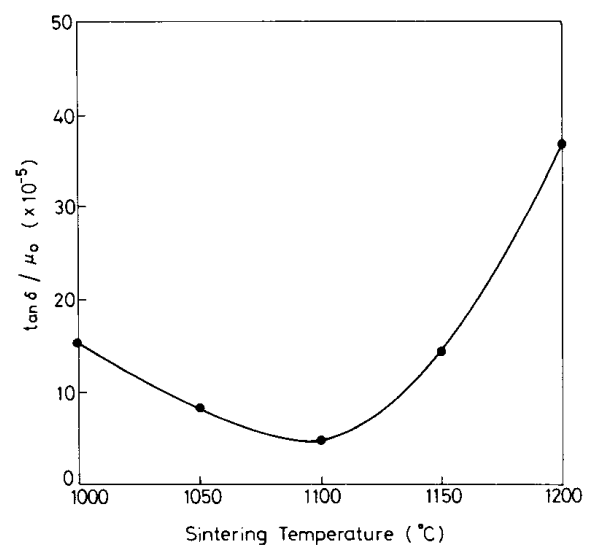

Fig. 8. Plot of $\tan \delta / \mu_{0}$ versus sintering temperature.

at $1100^{\circ} \mathrm{C}$. This value is believed to be related to an optimum microstructure which is achieved by sintering at $1100^{\circ} \mathrm{C}$. As shown in Figs. 1,2 , and 5 , at this $1100^{\circ} \mathrm{C}$ temperature, the sample reached nearly maximum attainable density, was composed of small and fairly uniform grain size, and showed no significant zinc loss.

\section{CONCLUSION}

The desired microstructure of low magnetic loss $\mathrm{Ni}-\mathrm{Zn}$ ferrite was produced through low-temperature sintering, without the use of sintering aids, of a relatively homogeneous green body, obtained by slip casting of colloidally precipitated ultrafine ferrite particles. The magnetic permeability for samples sintered at temperatures below $1100^{\circ} \mathrm{C}$ is proportional to (grain size) $)^{1 / 2}$, but this relation does not hold for samples sintered at temperatures higher than $1100^{\circ} \mathrm{C}$ due to volatilization of zinc.

\section{REFERENCES}

[1] T. Y. Tseng and J. C. Lin, "Preparation of fine-grained Ni-Zn ferrites," J. Mater. Sci. Lett., vol. 8, pp. 261-262, 1989.

[2] T. Y. Tseng and C. C. Fu, "Improving the microstructure of isotropic barium ferrite obtained via the colloidal filtration route, " $J$. Mater. Sci. Lett., vol. 6, pp. 351-352, 1987.

[3] R. L. Fullman, "Measurement of particle sizes in opaque bodies," Trans. AIME, vol. 197, no. 3, pp. 447-52, 1953.

[4] B. Francois and W. D. Kingery, in Sintering and Related Phenomena, G. C. Kuczynski, N. A. Hooton, and C. F. Gibbon, Eds. New York, NY: Gordon and Breach, 1967, pp. 499-525.

[5] P. F. Bongers, F. Broeder, J. Damen, P. Franken, and W. Stacy, "Defects, grain boundary segregation, and second phases of ferrites in relation to the magnetic properties," in Ferrites: Proc. Int. Conf. (Japan, Sept.-Oct. 1980), pp. 265-271.

[6] S. I. Pyun and J. T. Baek, "Microstructural dependence of permeability and permeability spectra in Ni-Zn ferrites," Amer. Ceram. Soc. Bull., vol. 64, no. 4, pp. 602-605, 1985.

[7] H. Igarashi and K. Okazaki, "Effect of porosity and grain size on the magnetic properties of Ni-Zn ferrites,"J. Amer. Ceram. Soc., vol. 60 , no. 1-2, pp. 51-54, 1977.

[8] K. Ishino and Y. Narumiya, "Development of magnetic ferrites Control and application of losses," Amer. Ceram. Soc. Bull., vol. 66, no. 10, pp. 1469-1474, 1987.

[9] J. Tasaki and T. Ito, "Effect of sintering atmosphere on the permeability of sintered ferrites," in Ferrites: Proc. Int. Conf. (Japan, July 1970), pp. 84-86.

[10] P. K. Gallagher, E. M. Gyorgy, and D. W. Johnson, Jr., "Relation between magnetic permeability and stoichiometry of $\mathrm{Mn}_{0.510} \mathrm{Zn}_{0.417} \mathrm{Fe}_{2.073} \mathrm{O}_{4+\delta}, "$ Amer. Ceram. Soc. Bull., vol. 57, no, 9. pp. 812-14, 1978 .

[11] M. I. Klinger and A. A. Samokhvalov, "Electron conduction in magnetite and ferrites," Phys. Status Solidi (b), vol. 79, pp.9-48, Jan. 1977.

[12] A. Globus, P. Duplex, and M. Guyot, "Determination of initial magnetization curve from crystallites size and effective anisotropy field," IEEE Trans. Magn., vol. MAG-7, no. 3, pp. 617-622, 1971.

[13] S. Chikazumi, Physics of Ferromagnetism (in Japanese), Tokyo, Japan: Syokabo, 1969.

[14] A. L. Stuijts, "Control of microstructures in ferrites," in Ferrites: Proc. Int. Conf. (Japan, July 1970), pp. 108-113.

T. Y. Tseng was born in Hong Kong on January 8, 1953. He received the M.S. degree in materials engineering in 1978, and the Ph.D. degree in electroceramics in 1982, both from the School of Materials Engineering, Purdue University, West Lafayette, IN.

He was briefly associated with the University of Florida prior to joining the National Chiao-Tung University, Hsinchu, Taiwan, Republic of China, in 1983. Presently, he is a Professor at the Institute of Electronics there. His interests are ceramic processing, electroceramics, and high-temperature ceramic superconductors.
J. C. Lin was born in Hwalen, Taiwan, on June 22, 1964. She received the B.S. degree in chemical engineering from Feng Chia University, Taiwan, and the M.S. degree from the Institute of Applied Chemistry, the National Chiao-Tung University, Hsinchu, Taiwan. Republic of China, in 1988.

She is a research associate at Materials Research Laboratories, Industrial Technology Research Institute, Chutung, Hsinchu. 